\title{
Forecasting of Cost Escalations in Post Disaster Construction with Special Reference to Tsunami Reconstruction in Sri Lanka
}

\author{
Lalith de Silva
}

\begin{abstract}
Since 1999, Sri Lanka tends to be in an area prone to natural hazards. In the recent past, the biggest devastation took place on 26th December 2004 when enormous destruction to both life and property was caused by a Tsunami. It was a recorded turning point as awareness was generated on losses and its consequences to the construction industry. In this context it was thought appropriate to initiate this research to find out the effects of natural disasters on construction cost.
\end{abstract}

After a comprehensive literature survey, it was observed that natural disasters have a direct relationship to construction cost increment in addition to increment in construct demand, the fuel price increment and inflation rate.

A unit was proposed to quantify the natural disasters as a guide line for establishing the relationship between construction cost increment and natural disasters. The unit named "ND" and

$1 \mathrm{ND}=10,000$ damaged or destroyed houses .

Statistical data analysis reveals that there is a positive and very strong relationship between natural disasters and construction cost increment (coefficient correlation is as high as 0.966). Another very significant issue is that when natural disasters take place in a particular year; the overall housing construction cost in the following year will be affected. This is because the overall reconstruction process and the time taken to constructing houses is very slow.

The construction cost of houses has gone up rapidly during recent past and the trend will keep away the desire of many to own a house. The ad hoc natural disasters have contributed to skyrocketing of the construction cost of house building.

\author{
ABBREVIATIONS \\ GDP - Gross Domestic Product \\ US - United States \\ ICTAD - Institute for Construction Training and \\ Development \\ NDMC - Natural Disaster Management Centre
}

\section{Introduction}

Natural Disasters have been occurring even longer than recorded history. People have suffered the consequences and withstand disasters. And the massive losses of life and property diverts normal flow of human life swiftly into real frustration.

In Sri Lanka, natural disasters like floods, landslides, droughts, sea erosion, environmental pollution, etc. are a frequent occurrence Many urban areas of Sri Lanka are prone to natural disasters. The consequences of natural disasters have direct impact on sustainable, broad-based development through out the country and also affect the urban community as well as their infrastructure and lifeline facilities.
As same as the prices of all the other Goods and Services, the prices of construction inputs go up with the general inflation. Natural Disasters is one of the crucial factors which influence sudden and immense deface in normal flow of price growth. Generally, construction projects deal with huge sums of money. With these unforeseen and often intolerable natural disasters, the normal price hike which originally keeps up with general inflation is shaken and pulls up to further height than the price escalation in a normal growing economy.

Sri Lanka is a developing country where a large part of the community belong to low income strata. A major 
satisfaction in life is to be an owner of a house and is thus a major desire. However, rapid price hike of construction inputs tends to keep that desire beyond reality.

\section{Aims and Objectives}

The research is mainly directed to identify and analyze the effects of natural disasters on construction cost and the forthcoming objectives going to be the supportive members in this way to accomplishment of the aforementioned aim.

- Explore the impact of natural disasters on built en vironment and its repercussions on the National Economic frame work.

- Identify the behavior of composite cost indices and general price indices.

- Analyze the fluctuation of cost indices of hous ing construction due to natural disasters.

\section{Methodology}

A comprehensive literature survey from books, journals, articles and electronic media sources provide information regarding the above objectives Interviewing professionals and other persons related to construction industry was done in catering to circumstances concerning the objectives

\section{Scope}

The analysis is confined to Sri Lanka. All housing cost indices are considered to analyze the fluctuations among different types of cost indices.

The damages and cost uplifts considered mainly in housing (construction) sector.

The period 1999 to 2005 was selected to achieve the objectives of this research.

\section{A disaster?}

"...an event, concentrated in time and space, in which a society (or a community) undergoes severe danger and incurs such losses to its members and physical appurtenances that the social structure is disrupted and the fulfillment of all or some of the essential functions of the society is prevented (Fritz, 1961).

\section{Types of Natural Disasters}

- $\quad$ Earthquake

- Volcanic eruption

- Tsunami

- $\quad$ Tropical cyclone (typhoon, hurricane)

- Flood

- $\quad$ Landslide

\author{
General Effects of Natural Disasters \\ Loss of life. \\ Injury. \\ Damage to and destruction of property. \\ Disruption of production. \\ Disruption of lifestyle.
}

\section{Economic Loss}

The Asian Region is extremely susceptible to natural disasters and attendant disasters due to earthquakes, cyclones/typhoons, landslides, floods or droughts. The annual economic loss due to disasters has been showing a major increase in the decades from 1950 to 2000 in developing countries. In 1950, slightly more than half the urban population at risk from earthquakes lived in these countries. The average economic loss was $\$ 4.9$ billion in 1960 , increased to $\$ 9.5$ billion in 1970 , and shot up to $\$ 15.1$ billion in 1980, and in 1990 multiplied five times to $\$ 76$ billion (Suresh,2002)

\section{NATURAL DISASTERS IN CONSTRUCTION POINT OF VIEW}

\section{Destructions}

In Sri Lanka, many urban areas are prone to frequent natural disasters like floods, landslides, droughts, sea erosion, environmental pollution, storm and strong wind are very common.. The consequences of natural disasters have direct impact on sustainable, broadbased development through out the country and also affect on urban community as well as their infrastructure and lifeline facilities.

In recent past Sri Lanka suffered much destruction from Floods and Land Slides. Additionally the Tsunami devastation which occurred in year 2004 caused the most damage to life and property in the recorded history of the country. Therefore the statistical data on reported disaster and amount of damages to buildings are collected only for above mentioned disasters.

\section{Direct effects on Buildings, according to type of disaster}

As noted, direct effects are mainly those related to loss of property. Natural phenomena cause direct damage to housing, causing partial or total destruction. Earthquakes tend to produce structural damage (in rafters, columns, paved areas, bearing walls, etc.) and nonstructural damage (light walls, installations, non-structural roofs, furnishings, equipment, etc.) in dwellings, due to the additional loads to which those elements are subjected by the earth's movements. Damage is also caused by permanent deformations of land (settling, slides, etc.) in land used for housing.

This section indicates several particularly relevant secondary effects arising from the destruction of housing, such as: 
a) Loss of income, which would normally be gener ated by or imputed to housing rental;

b) Variations in housing sector employment rates;

c) Effects on the balance of payments;

d) Effects on the public sector;

\section{Reasons behind the Construction Cost boosting due to Natural Disasters}

- Shortages of Construction Material used for re constructing

- Contamination of existent materials, plant and machineries

- Labour Shortage and Frustration of social minds

- Low Strength of land

- Disaster resistance building structures and de signs

A growth rate of 9.0 percent was estimated for the construction industry for the year 2005 as against the growth rate of 5.9 percent for 2004 . The estimates of value added of construction industry have been compiled by using material approach. This information is used together with the construction indicators and prices given by Institute for Construction Training and Development ICTAD.

The availability of materials such as total cement quantity, values of imported construction materials and local materials have increased by 32.1 per cent, 23.4 percent and 39.5 per cent respectively in 2005 from 2004. As a result of Tsunami destruction in December 2004 many reconstruction and rehabilitation activities have taken place in 2005 in the coastal belt as a recovery process. It is necessary to record that the various Tsunami recovery inputs such as machinery and equipment and labour contributions from various Institutions and countries (except donations which are considered as transfers) have not been captured completely due to poor data records. Those also made value added contributions to the economy. During the reference year 2005, reconstruction of infrastructure facilities such as roads, bridges, pipelines, telecommunication lines have taken place in. Similarly, during this reference period, rehabilitation of damaged schools and other public buildings, fishery harbours reconstruction of boats, hotels and restaurants also took place. 176 $\mathrm{km}$. of signaling and communication network of railway, railway bridges, railway stations and sub stations, $160 \mathrm{~km}$. of rail track were reconstructed after Tsunami destruction. These have been reflected in these estimates (national accounts of Sri Lanka - 2005)

\section{Reasons behind the Construction Cost boost- ing due to other factors}

\section{Population}

In most markets, rising population shifts demand curves out (Henderson, 1991). Food, clothing and shelter are main consumer goods in a market. Demand for these consumer goods arises from factors that affect the consumers who buy these goods (Henderson, 1991). As Henderson (1991) illustrates, demand for raw materials of manufacturing above consumer goods also arise with increasing demand. So the demand for construction inputs also arise with the increasing demand for construction outputs, which are the productive inputs of construction industry. It is often said that the demand for construction output, as it is largely for investment goods, will be more subject to fluctuations than demand for other consumer goods and services (Turin,1975).

\section{Inflation rate}

According to Stone (1966) the rate at which the value of money falls is the inflation rate. When the value of money is fallen considerably. As Stone (1966) describes, the ability to purchase buildings is declined due to the increase of cost of construction with this inflation rate.

\section{Fuel price increment}

According to Michael (2005), the increase in oil prices have a negative impact on global economic growth, and increases prices in general. This is because industries are one of key factors to economy of country and oil is needed for industry. Therefore, oil price increases, willhave an adverse impact on economies of countries. Further, the developing countries are the countries which are mostly going to be affected by the recent oil price movements (Sendooran, 2006)

\section{RESEARCH METHODOLOGY}

This chapter describes the underlying methodological assumptions and the analytical techniques adopted in this research. Multiple data sources were utilized where possible. The collected data was then analyzed using 'grounded theory'

\section{Data collection}

Data collection methods included: semi-structured and un-structured interviews with crucially placed organizational personnel, use of published and unpublished documents like, Journal publications, Thesis, Books, Government and industry reports, Conference proceedings, Undergraduate dissertations, Magazines, Internet Browsing 


\section{Analysis}

It was decided that the most appropriate method of analysis for the collected quantitative data was 'grounded theory'. That is, the research produces results in which the theory is grounded in the data. Support for this position comes from Martin and Turner (1986, cited Toft,1994) who wrote:

Grounded theory is particularly well suited to dealing with qualitative data of the kind gathered from semistructured or unstructured interviews, from case study material or certain kinds of documentary sources. The grounded theory approach offers the researcher a strategy for sifting and analyzing material of this kind.

\section{Findings}

After a comprehensive literature survey, several factors which can influence in upgrading the construction cost of housing could identify. Those are,

$\begin{array}{ll}\text { - } & \text { Natural disasters } \\ \text { - } & \text { Construction demand } \\ \text { - } & \text { Fuel price } \\ & \text { Inflation }\end{array}$

\section{The unit proposed for Natural Disasters}

The unit was proposed only as a guideline to search out the relationship with factors such as construction demand, fuel indices, and inflation. Proposal is as follows,

- Get total number of destroyed (a) and damaged (b) houses in particular year $(a+b)$

- $\quad$ Divide it from 10,000. $(a+b) / 10,000$

- $1 \mathrm{ND}$ is the unit

- $1 \mathrm{ND}$ : - If there are 10,000 damaged and/or de stroyed houses from the disaster or disasters, the number of natural disasters is $1 \mathrm{ND}$.

\section{Reasons behind the Selection}

- $\quad$ Although figuring out number of partially damaged and destroyed houses and their loss es may fulfill this task, data is only available on number of partially damaged and destroyed houses in between 1974 - 2005. There are no proper records of damaged or destroyed non residential buildings and infrastructures. There is no proper records on losses occurring to each building due to natural disasters to the build ings.

- Total number of damaged and destroyed hous es has been obtained to indicate the total de struction by the natural disasters. When the number of damaged houses is less in amount, it may not affect much to the construction cost. But when this amount be comes high (above 10,000) it may affect con struction cost significantly.

- $\quad$ Indicating the number of Natural Disasters oc curred in a simple manner will help the identifica tion and comparison of Natural Disasters with other factors affecting construction cost indices. According to the past data, the total number of damaged and destroyed houses is laid between 'zero' to '100,405' per year. Therefore 10,000 seem as the most suitable number to divide the total (according to proposed unit).

- $\quad$ The past data only reveals the number of dam aged and destroyed houses. It does not give an idea about the magnitude of damage and de struction and about the nature of the affected houses. Therefore considering the sample with a massive amount (like 10,000) will minimize the possible errors, by distributing the uncertain ty among the total.

\section{Comparison between natural disasters and increment of cost indices}

Below graph shows the figures of natural disasters and increment of cost indices in each year which plotted combining figures from table 1

Table 1 - Figures of the factors affecting to the increment of all housing cost indices

\begin{tabular}{|r|r|r|r|r|r|}
\hline Year & $\begin{array}{c}\text { All Housing } \\
\text { Cost Indices } \\
\text { Increment }\end{array}$ & $\begin{array}{c}\text { Natural } \\
\text { Disasters } \\
\text { (ND) }\end{array}$ & $\begin{array}{c}\text { Cumulative } \\
\text { Population } \\
\text { Increment } \\
\text { (\%) }\end{array}$ & $\begin{array}{c}\text { Fuel Indices } \\
\text { Increment } \\
(\%)\end{array}$ & $\begin{array}{r}\text { Inflation } \\
\text { Rate (\%) }\end{array}$ \\
\hline 1999 & 1.35 & 5.06 & 1.52 & 0.00 & 4.70 \\
\hline 2000 & 5.50 & 5.74 & 2.94 & 22.75 & 6.20 \\
\hline 2001 & 11.23 & 0.01 & 4.38 & 63.54 & 14.20 \\
\hline 2002 & 6.87 & 1.08 & 5.85 & 13.20 & 9.60 \\
\hline 2003 & 4.99 & 5.62 & 7.14 & 6.67 & 6.30 \\
\hline 2004 & 10.77 & 10.04 & 8.23 & 37.50 & 7.60 \\
\hline 2005 & 21.80 & 0.01 & 9.29 & 13.63 & 11.60 \\
\hline 2006 & 13.70 & 0.00 & - & 11.80 & - \\
\hline
\end{tabular}

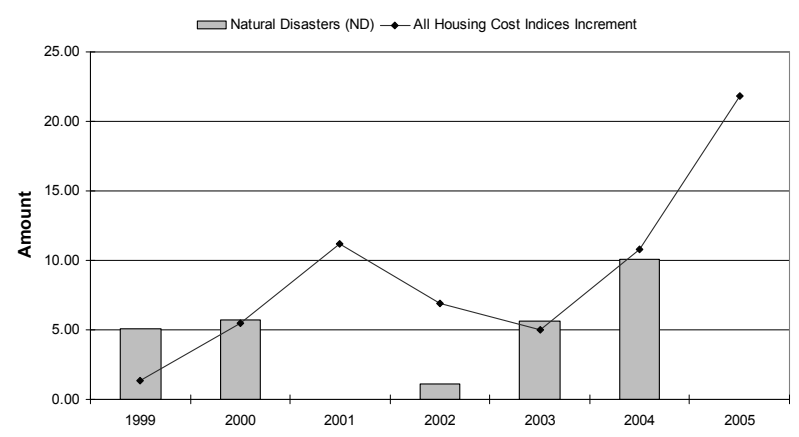

Year

Natural disasters Vs All Housing Cost Indices Increment

The above graph does not visualize any clear relationship between number of natural disasters and increment of cost indices in each year. Although it does not indicate any relationship at a glance, a careful study on this data reveals a relationship among them as discussed below. 
The increment of Cost Indices is $1.35 \%$ in year 1999 , relate to year 1998 and this figure is comparatively small. The amount of natural disaster in 1998 is 0.22 ND which also small. As shown in fig:- 11 within this one year period there is no any significant change in other factors also.

\section{0}

The growth rate of cost indices is 5.50 in year 2000 . The amount of damaged and destroyed houses in year 1999 is 50,591 (5.06 ND). The percentage of destroyed houses is $82 \%$ from this amount. The growth rate of cost indices has increased 3 times compared to previous year. It shows a high relationship of natural disasters on increment of cost indices. Nowadays Sri Lanka has a demand for 100,000 houses per year (Central Bank report 2005). This year, an additional and sudden demand arose for about 40,000 houses and renovation for about 9,000 houses. Definitely this caused massive impact on sudden change of cost indices growth rate and it is clearly shown in the graph.

\section{1}

The increment of cost indices has risen up to $11.23 \%$ in this year relate to year 2000. In addition to that, growth of fuel indices has taken place in this year. The year 2000 has 5.74 ND. But the relationship between cost indices growth and fuel indices growth is small (Annexure 1). There are no considerable changes in other factors also. Hence the major contribution is caused by the natural disasters for the increment of cost indices.

\section{2}

The increment of cost indices has declined to $6.87 \%$ in this year. Other factors also do not have any significant changes. And also it is noted Sri Lanka has not suffered with any kind of natural disasters in year 2001. It points to the fact that when natural disasters are nil, the increment of cost indices is minimum.

\section{3}

In 2001 it is indicated that 1.08ND natural disasters have taken place in year 2002. The number of damaged houses is 10,779 and no destroyed houses. This will not impact on overall construction cost of Sri Lanka. As a result of that the growth rate of cost indices has further declinedto $4.99 \%$. It again emphasizes that when the amounts of natural disasters are nil or less (around 1.00 ND); the growth of cost indices is less.
Immense destruction occurred in year 2003 due to major flood. The amount is $5.62 \mathrm{ND}$. Once the growth rate of cost indices has became higher as $10.77 \%$ in year 2004. Even though the inflation rate is very small (inflation rate in this year is 2.51), the overall construction cost has risen. Therefore it can be concluded that the growth rate of cost indices goes up with the amount of natural disasters. (Up to $5.00 \mathrm{ND}$ or around $5.00 \mathrm{ND}$ this effect is considerably visible).

\section{5}

In recent past the biggest destruction has occurred in year 2004. The amount is 10.04 ND. The highest growth rate of cost indices also reported in this year as $21.80 \%$. So the amount of damaged and destroyed houses by natural disasters is greater than the normal housing demand in the Sri Lanka in year 2005. Hence a great impact occurred due to natural disasters on the increment of overall construction cost. In addition to that there is no considerable change in other factors. Therefore the main reason for construction cost increment seems as natural disasters.

\section{6}

Again minimum number of natural disasters took place in year 2005. And the rate of cost indices growth has declined in year 2006 related to previous year.

\begin{tabular}{|c|c|c|c|c|c|c|c|c|}
\hline Year & $\mathbf{1 9 9 9}$ & $\mathbf{2 0 0 0}$ & $\mathbf{2 0 0 1}$ & $\mathbf{2 0 0 2}$ & $\mathbf{2 0 0 3}$ & $\mathbf{2 0 0 4}$ & $\mathbf{2 0 0 5}$ & $\mathbf{2 0 0 6}$ \\
\hline $\begin{array}{c}\text { Cost Indices } \\
\text { Increment }\end{array}$ & 1.35 & 5.5 & 11.23 & 6.87 & 4.99 & 10.77 & 21.8 & 13.7 \\
\hline $\begin{array}{c}\text { Natural } \\
\text { Disasters } \\
\text { (ND) }\end{array}$ & 0.22 & 5.06 & 5.74 & 0.01 & 1.08 & 5.62 & 10.04 & 0.01 \\
\hline
\end{tabular}

Table 02 Relationship between All Housing Cost Indices increment and Natural Disasters

\section{Conclusion of the Discussion}

Above circumstances demonstrate that there is a clear relationship between the increment of cost indices and the natural disasters. The most important factor which I realized through the above study which I want to emphasize here is that increment of cost indices in a particular year has a relationship to the number of natural disasters occurred in the previous year. The reasons behind that can state as follows

\section{- Reconstruction process is normally very slow \\ - Time taken to construct a house}

In the reconstruction stage, the major portion of construction works will be carried out in the year following the year when natural disasters occurred. Therefore when natural disasters take place in a particular year, it will affect the increment of cost indices in next year. In addition to that, slight amounts in the number of natural disasters (like $0.05,0.01$ ) will not influence the 
increment of cost indices. It is understandable that if the amount of natural disasters goes up (5.00 ND or around $5.00 \mathrm{ND}$ ), the increment of cost indices also occurs.

There is a positive value in the increment of cost indices annually. That means the increase in construction cost takes place continuously. The cost indices have risen even without natural disasters. Reason behind this is the impact of other factors on increment of cost indices. Their impact is comparatively less, regular and not spontaneous. Hence the continuous construction cost increase is continuing trend.

With this emphasizing discussed earlier, that the cost indices in a particular year is influenced by the number of Natural Disasters occurring in previous year, the above graph has been updated by shifting one year ahead the existing natural disaster columns for the sake of easy identification and clear comparison as follows.

\section{Relationships}

Relationship between All Housing Cost Indices increment and Natural Disasters

The coefficient correlation between these two factors is 0.933; hence there is positive and very strong relationship. As natural disasters are not regular events and happen suddenly, using of strongest points on past data on analyzing the effect of them on the construction cost will give more accurate out put figures. Hence the most strong points from above graph are recognized and their relationships are analyzed as below.

\begin{tabular}{|c|c|c|c|c|}
\hline Year & 2000 & 2001 & 2004 & 2005 \\
\hline \multicolumn{5}{|l|}{ Cost Indices Increment } \\
\hline & 5.5 & 11.23 & 10.77 & 21.8 \\
\hline $\begin{array}{c}\text { Natural Disasters } \\
\text { (ND) }\end{array}$ & & & & \\
\hline & 5.06 & 5.74 & 5.62 & 10.04 \\
\hline
\end{tabular}

Table 3: - Relationship between All Housing Cost Indices increment and Natural Disasters (Strong Points)

The coefficient correlation between All Housing Cost Indices increment and Natural Disasters (Strong Points) is 0.966; hence there is positive and very strong relationship.

As results of relationships of above factors, the population growth and inflation rate have positive relationship with the cost indices increment. Fuel indices increment positive but weak relationship.

The relationship between the natural disasters and the increment of cost indices has positive and very strong relationship.

\section{Equation}

Natural disasters have a positive and very strong relationship with increment of cost indices. Therefore the data of cost indices increment and natural disasters can show through scatter diagram as follows. (With regards to table y)

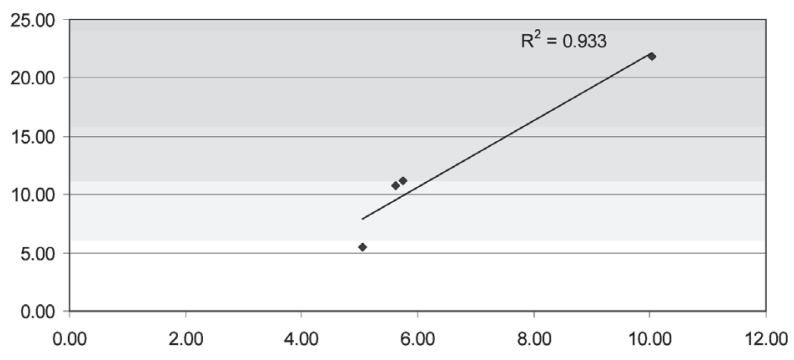

\section{Scatter Diagram of Increment of All Housing Cost Indices Vs Natural Disasters}

As seen in the graph, there is proper distribution of scatters. The equation of the line in the graph can propose as a estimation equation for cost indices increment in next year relate to the amount of natural disasters occurs in particular year.

\section{$Y=2.8652 X-6.6294$}

$\mathrm{Y}=$ cost indices increment (following year relate to
particular year)

$X=$ number of natural disasters (in particular year)

As mentioned earlier, the number of natural disasters occurred in particular year affect on the cost indices increment of next year. Therefore if the value of ND can be accurately recorded it is possible to predict the cost indices increment in following year.

To work out a precise estimated figure for cost indices increment; the number of natural disasters should be around or above to the $5.00 \mathrm{ND}$. This because of, the most strong points are taken into account when determining the equation.

\section{Conclusion}

The construction cost of the buildings, whether it is a house or commercial building, has increased dramatically in modern days. The major reason for that can be mentioned as price increment of construction inputs such as material, labour and plant and equipment. There are some causes to uplift the price of construction inputs. They are, Natural Disasters, Increment of Construction Demand, Inflation Rate, and Increment of Fuel Prices

With the recurrent scenarios like increment of construction demand, Inflation rate and increment of fuel prices, the construction cost normally rise up. But with the ad hoc occurrence of natural disasters, the regular growth of construction cost has defaced. This will hamper precise construction cost forecasting. Therefore the finding out the relationship between construction cost and natural disasters has become a timely necessity. Possible approaches have taken with the 
available data to find out the context between the construction cost and the natural disasters.

The most important factor which should be expressed here is, all the assumptions, discussions, relationships and forecasting has been carried on the ground of available data. There are no proper recorded data of cost losses regarding the destruction by natural disasters in each year. The other data such as population, fuel and inflation are common to the all island. Therefore the appropriateness of all predictions is based on the reliability of the data. And also the number of available data sets for all factors such as cost indices increment, natural disasters, population growth, inflation rate and increment of fuel indices are few.

Hence it is very hard to give precise figure through statistical data analysis to demonstrate the contribution of natural disasters to the increment of cost indices. According to this research methodologies and philosophies, finding outs as follows.

Through a careful study on the context between natural disasters and increment of cost indices, there is an inherent relationship between them. Even though the other factors such as cumulative population growth, inflation rate and increment of cost indices have positive relationship with the increment of all housing cost indices, the natural disasters have a positive and very strong relationship (coefficient correlation $=0.935$ ) with the increment of all housing cost indices according to the statistical data analysis.

Another very important visible fact emanated from the data is, when the natural disasters take place in a particular year, it influence by the increment of cost indices in following year. The reasons behind such kind of relationship can noticeable as Time taken to settle down the frustrated minds, Reconstruction process is normally very slow, Time taken to construct a house. Therefore if natural disasters occurred in a particular year, the large parts of reconstruction works will be carried out in the next year. Hence the cost indices of following year will increase.

Analyzing the data of increment of cost indices and the number of natural disasters occurred, it shows a linear relationship. Therefore the cost indices increment of following year can be predicted through the equation of regression line of the scatter plot diagram, when number of natural disasters take place in a particular year. The equation as follows,

\section{$Y=2.8652 X-6.6294$}

$Y=$ cost indices increment (following year relate to particular year)

$X=$ number of natural disasters (ND in particular year)
When deriving the equation, only the strong and significant data points were only considered and the data points which are below and around 1.00 ND are eliminated. This is because very small number of NDS can not affect significantly to change the overall construction cost of the country. It was clear that housing cost indices prediction can be accurate only when the number of natural disasters is above and around the $5.00 \mathrm{ND}$.

\section{Recommendation}

It is better to prepare for the prevention of natural disasters rather than suffering. Some experts estimate that for every dollar invested in disaster preparedness, you will save six dollars in reconstruction cost (Munich Re, 2005). The construction cost increment due to natural disasters cannot be avoided but can decrease with the appropriate disaster resistant and cost effective building technologies and materials use in both reconstructions and new constructions stages. In the same time can reuse the debris and cost effective building materials in construction phase. Hence, it will reduce the overall construction cost.

Specially the Quantity Surveyors and other professionals and relevant parties to the construction industry should be aware of these aspects and the recommendations of this research to their appropriate cost estimations, project planning, and risk management and other management and cost aspects of the construction projects.

There was a great difficulty in finding out the reliable and continuous data records in quantifying the relationship between the increment of cost indices and the natural disasters through statistical data analysis. This was because due to less availability of the recorded data; the exact quantification of the relationships could not be achieved. Therefore, it is essential to keep proper, precise, comprehensive and continuous data by the relevant departments, institutions and authorities like Statistical and Census department, ICTAD, and Natural Disasters

\section{Further Research}

With the collection of more data on cost indices, construction demand, inflation rate and natural disasters, and with the innovative thinking; this research also can carry out further to an in-depth study.

In addition to that the following research areas have surfaced and those will be supportive roles for the above research area.

- Effects of inflation rate on construction cost

- Effects of construction demand on construction cost 


\section{References}

\section{Books}

BROWN, J. AND SIME, J.A., 1981. Methodology for accounts in social method and social life. 3rd ed. London: Routledge.

CARTER, W.N., 1985. Procedures and Guidelines for Disaster Preparedness and Response. Oxford: Butterworth-Heinemann Ltd.

CARTER, W.N., 1991. Disaster management: A Di saster manager's hand book. Manila: Asian Development Bank.

DRABEK, T.E., 1986. Human system responses to disaster. New York: Springler-Verlag.

FRITZ, C. E., 1961. "Disaster", in Contemporary Social Problems.USA: Merton and Nisbet.

HENDERSON, J. V. AND POOLE, W., 1991. Princi ples of macroeconomics. LEXINGTON: D.C. HEATH AND COMPANY.

SMITH, K., 1991. Environmental hazards: Assess ing risk and reducing disaster. 3rd ed. Lon don: Routledge.

TOFT, B., 1994. Learning from Disasters. Oxford: Butterworth-Heinemann Ltd.

TURIN, D. A., 1975. Aspects of the economics of construction. London: George Godwin Ltd.

STONE, P. A., 1966. Building economy. 3rd ed. Lon don: Pergamon Press Ltd.

SPATZ, C., 1993. Basic statistics. 5th ed. Wads worth: Belmont California.

\section{Publications from corporate bodies}

2005. Annual Report 2005. Colombo: Central Bank of Sri Lanka.

ICTAD, 2006. Bulletin of construction statis tics. Colombo: Ministry of Urban Develop ment Construction \& Public Utilities.

2005. National Accounts Sri Lanka, Colombo, Department of Census and Statistics.

UNITED NATIONS, 1987. Disaster preven tion and mitigation. New York: United $\mathrm{Na}$ tions.

UNITED NATIONS, 1991. Mitigation natural disasters. New York: United Nations

\section{Electronic materials}

(2005). Consumer Price Indices and Infla tion [online]. Colombo, Central Bank of Sri Lanka. Available from: http:// www.central banklanka.org/ prices indices inflation.html [Accessed 01 October 2006]

SURESH, V.(2002). Promoting safer build ing construction [online]. India, CMD. Avail able from: http://www.adpc.net/audmp/rllw/ PDF/PSB.pdf [Accessed 15 September 2006]

\section{Dissertations}

SENDOORAN, B., 2006. Impact of oil price increases in construction industry. 